\title{
Comparative Analysis of Automatic versus Fixed Positive Airway Pressure Therapy for Severe Obstructive Sleep Apnea
}

\author{
Ilyoung Cho' ${ }^{1}$, Hwabin Kim ${ }^{1}$, Kuen-Ik $\mathrm{Yi}^{2}$, Sung-Dong Kim¹, \\ Sue Jean Mun', and Kyu-Sup Cho ${ }^{1,3}$ (B) \\ ${ }^{I}$ Department of Otorhinolaryngology-Head and Neck Surgery, Pusan National University School of Medicine, Pusan National University \\ Hospital, Busan; and ${ }^{2}$ Department of Otorhinolaryngology-Head and Neck Surgery, Pusan National University School of Medicine, \\ Yangsan Pusan National University Hospital, Yangsan; and ${ }^{3}$ Biomedical Research Institute, Pusan National University Hospital, \\ Busan, Korea
}

\author{
중증 폐쇄성 수면무호흡증에서 자동형 양압기와 고정형 양압기 치료의 비교 분석 \\ 조일녕 ${ }^{1} \cdot$ 김화빈 $^{1} \cdot$ 이근익 $^{2} \cdot$ 김성동 $^{1} \cdot$ 문수진 $^{2} \cdot$ 조규섭 $^{1,3}$ \\ 부산대학교 의학전문대학원, 부산대학교병원 이비인후과, ${ }^{1}$ 부산대학교 의학전문대학원, 양산부산대학교병원 이비인후과학교실, ${ }^{2}$ \\ 부산대학교병원 의생명연구원 ${ }^{3}$
}

\author{
Received September 4, 2019 \\ Revised January 1, 2020 \\ Accepted January 16, 2020 \\ Address for correspondence \\ Kyu-Sup Cho, PhD \\ Department of Otorhinolaryngology- \\ Head and Neck Surgery, \\ Biomedical Research Institute, \\ Pusan National University \\ School of Medicine, \\ Pusan National University Hospital, \\ 179 Gudeok-ro, Seo-gu, \\ Busan 49241, Korea \\ Tel +82-51-240-7824 \\ Fax +82-51-246-8668 \\ E-mail choks@pusan.ac.kr
}

Background and Objectives The purposes of this study were to compare the purchase rate and adherence regarding the use of two machines, continuous positive airway pressure (CPAP) and automatic positive airway pressure (APAP), and to determine associated factors affecting the purchase rate and adherence of PAP in the treatment of severe obstructive sleep apnea (OSA). Subjects and Method From March 2016 to December 2017, 45 patients diagnosed with severe OSA by polysomnography were enrolled in this study. Patients were prescribed CPAP or APAP by one doctor and allowed to decide whether to purchase the machine after a one-month lease period, which was identified as the purchase rate. Adherence was identified as using the machine $4 \mathrm{~h} /$ night on $70 \%$ of nights following the PAP therapy of three months.

Results The adherence rate of CPAP (84\%) was statistically and significantly higher than APAP $(55 \%)(p=0.033)$. However, there was no significant difference in the adherence rate between CPAP (76\%) and APAP (63\%). The mean pressure and 95th percentile leak were $8.62 \mathrm{~cm}_{2} \mathrm{O}$ and $12.97 \mathrm{~L} / \mathrm{min}$ in the $\mathrm{CPAP}$ and $10.55 \mathrm{~cm} \mathrm{H}_{2} \mathrm{O}$ and $20.36 \mathrm{~L} / \mathrm{min}$ in the APAP, respectively. The mean pressure and 95th percentile leak were significantly lower in CPAP than in APAP $(p=0.010$ and $p=0.014$, respectively).

Conclusion Although adherence was not significantly different, the purchase rate was significantly higher in the fixed CPAP than in APAP, which may have been influenced by high pressure and leak patients experienced when using the particular PAP machine.

Korean J Otorhinolaryngol-Head Neck Surg 2020;63(3):108-13

Key Words Continuous positive airway pressure $\cdot$ Patient compliance ·

Sleep apnea, obstructive.

This is an Open Access article distributed under the terms of the Creative Commons Attribution Non-Commercial License (https://creativecommons.org/licenses/by-nc/4.0) which permits unrestricted non-commercial use, distribution, and reproduction in any medium, provided the original work is properly cited. 


\section{서 론}

폐쇄성 수면무호흡증(obstructive sleep apnea, OSA)은 수 면 중 반복적인 상부기도의 비정상적인 폐쇄가 특징인 질환 으로 수면장애, 주간 졸림증, 심혈관계 후유증의 위험 증가, 업무 수행 능력 저하, 삶의 질 저하 등을 초래할 수 있다. ${ }^{1-3)}$ 폐쇄성 수면무호흡증의 유병률은 미국의 경우 여성의 $2 \%$ 와 남성의 $4 \%$ 에서 관찰되고 국내에서도 여성의 $3.2 \%$ 와 남성의 4.5\%에서 폐쇄성 수면무호흡증이 관찰된다. ${ }^{4.5)}$ 폐쇄성 수면무 호흡증의 치료 방법으로 체중 감량, 수면 자세 교정과 같은 보존적인 방법뿐 아니라, 구강 내 장치, 상기도 부위에 대한 수술적 치료 증이 제시되고 있지만, 가장 주된 치료법으로는 양압기(positive airway pressure, PAP)를 들 수 있겠다.

PAP는 1981년 Sullivan 등에에 의해 처음 소개된 이후, 여 러 연구에서 폐쇄성 수면무호흡증의 매우 효과적인 치료 방 법으로 인정받았다. PAP는 상기도 부위에 지속적인 양압의 공기를 주입하여 수면 중 일어나는 상기도의 폐쇄된 부위를 열어 상기도에 공기 부목(pneumatic splint)을 형성하는 장 치로, 호흡에 대한 저항을 감소시키며, 상기도의 면적을 증가 시켜 수면 중 일어나는 상기도 폐쇄를 개선시킨다.) PAP 치 료는 중등도 이상의 폐쇄성 수면무호흡증을 가진 환자에서 표준 치료법이 되었으며,9) $\mathrm{PAP}$ 를 지속적으로 사용하면 수 면무호흡증의 중증도 감소, 주간 졸림증, 삶의 질, 수면의 질, 고혈압의 호전, 심혈관계 위험 감소 등의 효과를 보인다고 보 고되었다. ${ }^{10-12)} \mathrm{PAP}$ 치료는 폐쇄성 수면무호흡증을 가진 환자 의 치료에 있어 많은 의학적 증거를 통해 가장 확실환 치료 효과를 보이는 것으로 알려져 있지만 환자들의 낮은 인식과 비강 마스크 불편감, 수면 방해, 구강 또는 안구 건조감, 비폐 색 등으로 인해 PAP 치료의 순응도는 낮다. ${ }^{13)} \mathrm{PAP}$ 치료의 순응도는 전세계적으로 28 83\% 정도로 다양하게 보고되고 있으며, ${ }^{14)}$ 국내에서도 이와 유사하여 $40 \%$ 전후의 순응도를 보이고 있다. ${ }^{15)}$

PAP 치료에는 적정압력검사를 통해 정해진 한 가지 압력만 지속적으로 전달하여 기도를 확보하는 고정형 양압기(continuous positive airway pressure, CPAP)를 사용할 수 있고, 고정된 압력으로 인해 환자가 느끼는 구강 또는 안구 건조감, 비폐색 등의 불편감을 감소시키기 위해 환자의 기도 내 흐름 제한이나 저항에 따라 정해진 범위 내에서 압력을 자동적으 로 조절하는 자동형 양압기(automatic positive airway pressure, APAP)를 적용할 수 있다. ${ }^{16,17)} \mathrm{APAP}$ 가 폐쇄성 수면무 호흡증 환자의 치료에 효과가 있으며 무작위 대조 연구에서 $\mathrm{APAP}$ 가 기도 폐쇄를 줄이고 수면의 질과 주간 졸림증을 개 선하는 데 $\mathrm{CPAP}$ 만큼 효과적이라는 결과를 보였지만, ${ }^{18,19)}$ 중
증의 수면무호흡증 환자에서 PAP 치료를 함에 있어 낮은 순 응도의 원인을 PAP 기기의 적정 압력과 연관을 지어 연구한 문헌은 많지 않다. 이에 저자들은 중증의 폐쇄성 수면무호흡 증 환자를 대상으로 $\mathrm{APAP}$ 과 $\mathrm{CPAP}$ 치료의 효과 및 구매율 과 순응도를 비교 분석하고, 구매율과 순응도에 영향을 미치 는 인자에 대해 알아보고자 하였다.

\section{대상 및 방법}

2016년 3월 2017년 12월까지 부산대학교병원에서 중증의 수면무호흡증으로 PAP을 처방받은 45명의 환자를 대상으로 진행하였다. 중증의 수면무호흡증은 level I 수면다원검사 (Embla N7000, Embla Systems, Broomfield, CO, USA) 에서 무호흡-저호흡 지수(apnea-hypopnea index, AHI)가 30 이상인 환자로 정의하였다. 본 연구에서는 PAP의 순응도 에 영향을 미칠 수 있는 비중격만곡증과 하비갑개 비대증, 알레르기비염, 만성 비·부비동염이 있거나, 이전에 비강 또는 구강의 수술력이 있는 경우는 연구에서 제외하였다. 이 연구 는 부산대학교병원 기관윤리심의위원회의 심의를 통과하였 다(H-1804-016-066).

각 환자들의 진료기록 및 수면다원검사 기록을 후향적으 로 검토하여 인구학적인 자료 및 신장과 체중으로 계산한 체 질량 지수(body mass index, $\mathrm{BMI}$ ), $\mathrm{AHI}$, 호흡장애지수 (respiratory disturbance index, RDI), 평균산소포화도, 최저산 소포화도, 주간졸림증척도(Epworth sleepiness scale, ESS) 와 같은 이학적 자료를 분석하였다.

Level I 수면다원검사에서 AHI가 수면 시간당 30회 이상 인 중증 OSA 환자들은 한 명의 의사로부터 동일한 비강 마 스크를 가진 CPAP(Airsense 10 Elite, Resmed, Australia) 또는 APAP(Airsense 10 Autoset, Resmed) 장치를 처방받은 후 기기 관리자로부터 PAP 기기를 4주간 임대하여 사용해 보고 지속적으로 사용할 의향이 있는 경우에 기기를 구매하 게 된다. $\mathrm{CPAP}$ 를 처방받은 환자의 경우는 적정압력검사 (PAP titration)를 통해 적정 압력을 결정하는 과정을 거친 후 한 가지 압력으로 적용하였고 $\mathrm{APAP}$ 의 경우 수면무호흡 의 증상에 반응하는 기계 자체의 컴퓨터 알고리즘에 맞춰 최 소 $4 \mathrm{~cm} \mathrm{H} \mathrm{H}_{2} \mathrm{O}$ 에서 최대 $15 \mathrm{~cm} \mathrm{H} \mathrm{H}_{2} \mathrm{O}$ 까지 압력이 변화하도록 적용하였다(Fig. 1).

본 논문에서는 PAP 기기를 구매하고 3개월이 지난 후에도 하루 4시간 이상 지속적으로 사용하였으며, 전체 기간의 $70 \%$ 이상의 일수에서 사용한 경우를 adherence, 그렇지 않은 경 우를 non-adherence로 정의하였고, 처방 4개월 후의 지속적 인 사용 여부를 PAP 기기에 저장된 데이터를 분석하여 조사 
하였다. ${ }^{20)} \mathrm{PAP}$ 기기에 저장된 데이터에서 APAP의 $95 \%$ 압력 (95th percentile pressure)과 CPAP의 고정 압력을 통해 적 정 압력을 구해 비교 분석하였으며, 95th percentile leak, 하 루 4시간 이상 PAP 사용 비율을 분석하였다. PAP 기기를 구 매하지 않았을 경우 비구매 사유를 비강 마스크 불편감, 효 과 없음, 경제적 이유로 분류하여 분석하였다.

$\mathrm{CPAP}$ 또는 APAP를 처방받은 환자군들 간의 인구학적인 자료 및 $\mathrm{BMI}, \mathrm{AHI}, \mathrm{RDI}$, 최저산소포화도, 평균산소포화도, ESS 수치, 양압기의 압력, 95th percentile leak, 하루 4시간 이상 PAP 사용 비율과 양압기 종류에 따른 PAP 치료에 대 한 구매율과 순응도 분석을 카이 제곱 검정(chi-square test) 또는 Fisher의 정확검정(Fisher's exact test)을 이용하여 시행 하였다. 모든 통계분석은 IBM SPSS Statistics 19(IBM Corp., Armonk, NY, USA)를 사용하여 시행되었고 $p$-value가 0.05 미만일 때 통계적 유의성이 있다고 판단하였다.

\section{결 과}

45명의 OSA 환자들에게 한 명의 의사가 CPAP 또는 APAP 을 처방하였고 $\mathrm{CPAP}$ 를 처방받은 환자는 25 명, $\mathrm{APAP}$ 를 처 방받은 환자는 20 명이었다. 각각의 PAP 처방에 따른 평균 나이는 CPAP에서 49.9세, APAP에서 49.2세였다. Freidman 병기에서 구개의 상태가 3 또는 4단계인 환자는 $\mathrm{CPAP}$ 가

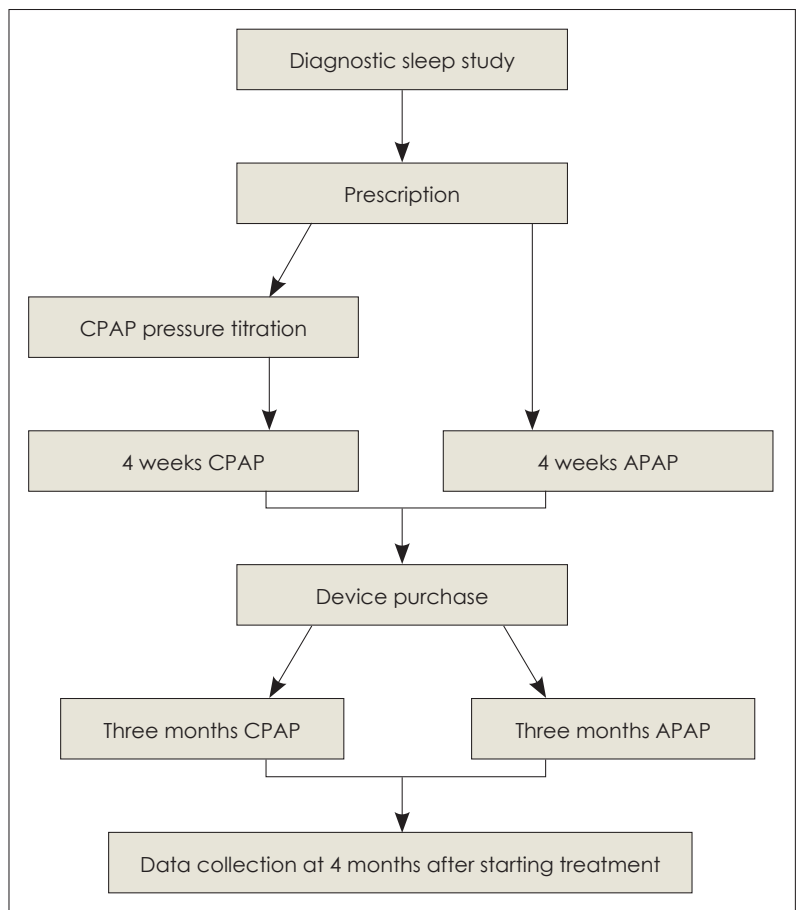

Fig. 1. Summary of the study protocol. APAP: automatic positive airway pressure, CPAP: continuous positive airway pressure.
20 명, APAP가 16 명이었고 편도의 크기가 3 또는 4단계인 환자는 $\mathrm{CPAP}$ 가 8명, $\mathrm{APAP}$ 가 4명이었다. BMI는 CPAP에서 28.3, APAP에서 27.7이고 $\mathrm{AHI}$ 는 $\mathrm{CPAP}$ 에서 57.6, APAP에 서 56.9였다. RDI는 CPAP에서 60.1, APAP에서 59.8이었으 며, 최저산소포화도는 $\mathrm{CPAP}$ 에서 $69.8 \%, \mathrm{APAP}$ 에서 $69.9 \%$ 이고 평균산소포화도는 $\mathrm{CPAP}$ 에서 $91.4 \%, \mathrm{APAP}$ 에서 $91.4 \%$ 였다. ESS 점수는 CPAP에서 9.2, APAP에서 10.3이었다. 환 자의 평균 나이, Freidman 병기에서 구개의 상태와 편도의 크기, $\mathrm{BMI}, \mathrm{AHI}, \mathrm{RDI}$, 최저산소포화도, 평균산소포화도, $\mathrm{ESS}$ 점수는 두 그룹 간에 통계적인 유의성은 없었고 그 외 고혈압, 당뇨와 같은 기저질환의 유무에 있어서도 두 그룹 간 에 통계적인 유의성은 없었다(Table 1).

$\mathrm{CPAP}$ 를 처방받은 환자 25 명 중 4 주간의 임대 후 $\mathrm{CPAP}$ 를 구매한 사람은 21 명(84\%), APAP를 처방받은 환자 20명 중 4주간의 임대 후 $\mathrm{APAP}$ 를 구매한 사람은 11 명(55\%)으로 $\mathrm{CPAP}$ 와 $\mathrm{APAP}$ 의 구매율이 통계적으로 유의한 차이가 있음 을 확인할 수 있었다 $(p=0.033)$. PAP 처방 후 4주간의 대여 후 구매를 한 환자들을 대상으로 PAP 치료 4개월 기간 동안 CPAP의 adherence는 21명 중 16명(76\%), APAP의 adherence는 11명 중 7명(63\%)로 CPAP에서의 순응도가 APAP에 비해 높았으나 통계학적으로 유의한 차이는 없었다 $(p=0.681)$

(Table 2).

비구매 사유에서 $\mathrm{CPAP}$ 의 경우 4명 중 3명(75.0\%)이 비강 마스크 불편감을 호소하였고 1명(25.0\%)이 효과가 없다고 하 였고 APAP의 경우 9명 중 6명(66.7\%)이 비강 마스크 불편감

Table 1. Demographic characteristics of obstructive sleep apnea for CPAP or APAP

\begin{tabular}{lccc}
\hline & CPAP $(n=25)$ & APAP $(n=20)$ & $p$-value \\
\hline Male & $25(100)$ & $18(90)$ & 0.192 \\
Age (years) & $49.9 \pm 14.7$ & $49.2 \pm 11.3$ & 0.866 \\
$\mathrm{HTN}$ & $8(32)$ & $4(20)$ & 0.366 \\
$\mathrm{DM}$ & $2(8)$ & $0(0)$ & 0.495 \\
FTP III, IV & $20(80)$ & $16(80)$ & 1.000 \\
Tonsil size 3, 4 & $8(32)$ & $4(20)$ & 0.366 \\
$\mathrm{BMI}\left(\mathrm{kg} / \mathrm{m}^{2}\right)$ & $28.3 \pm 3.9$ & $27.7 \pm 2.1$ & 0.518 \\
$\mathrm{AHI}($ events/h) & $57.6 \pm 19.7$ & $56.9 \pm 24.0$ & 0.913 \\
$\mathrm{RDI}($ events/h) & $60.1 \pm 21.5$ & $59.8 \pm 20.4$ & 0.936 \\
$\mathrm{SaO}_{2}$ min $(\%)$ & $69.8 \pm 8.5$ & $69.9 \pm 10.3$ & 0.958 \\
$\mathrm{SaO}_{2}$ mean $(\%)$ & $91.4 \pm 3.0$ & $91.4 \pm 3.2$ & 0.955 \\
$\mathrm{ESS}$ & $9.2 \pm 4.6$ & $10.3 \pm 4.9$ & 0.423 \\
\hline
\end{tabular}

Data are expressed as the number (percentage) except age, $\mathrm{BMI}, \mathrm{AHI}, \mathrm{SaO}_{2} \mathrm{~min}$, and ESS (means \pm standard error of the mean). AHI: apnea-hypopnea index, APAP: automatic positive airway pressure, BMl: body mass index, CPAP: continuous positive airway pressure, DM: diabetes mellitus, ESS: Epworth sleepiness scale, FTP: Friedman tongue position, HTN: hypertension, RDI: respiratory disturbance index 
Table 2. Purchase rate, compliance rate according to CPAP or APAP

\begin{tabular}{lccc}
\hline \multicolumn{1}{c}{ Variables } & CPAP $(n=25)$ & APAP $(n=20)$ & p-value \\
\hline Purchase & $21(84)$ & $11(55)$ & 0.033 \\
Compliance & $16(76)$ & $7(63)$ & 0.681 \\
\hline
\end{tabular}

Data are expressed as the patients' number (percentage). APAP: automatic positive airway pressure, CPAP: continuous positive airway pressure

Table 3. Non-purchase reason according to CPAP or APAP

\begin{tabular}{lcc}
\hline \multicolumn{1}{c}{ Variables } & CPAP $(n=4)$ & APAP $(n=9)$ \\
\hline Nasal mask discomfort & $3(75.0)$ & $6(66.7)$ \\
No effect & $1(25.0)$ & $3(33.3)$ \\
\hline
\end{tabular}

Data are expressed as the patients' number (percentage). APAP: automatic positive airway pressure, CPAP: continuous positive airway pressure

Table 4. PAP device data at the 16-week follow-up

\begin{tabular}{lccc}
\hline \multicolumn{1}{c}{ Variables } & CPAP & APAP & p-value \\
\hline Mean pressure $\left(\mathrm{cm} \mathrm{H}_{2} \mathrm{O}\right)$ & $8.6 \pm 2.0$ & $10.6 \pm 1.6$ & 0.010 \\
95th percentile leak $(\mathrm{L} / \mathrm{min})$ & $13.0 \pm 8.2$ & $20.4 \pm 6.1$ & 0.014 \\
Used days $\geq 4 \mathrm{hrs}(\%)$ & $74.0 \pm 23.8$ & $65.1 \pm 25.7$ & 0.340 \\
AHI (events $/ \mathrm{h})$ & $2.7 \pm 1.6$ & $2.6 \pm 1.7$ & 0.949
\end{tabular}

Data are expressed as means \pm standard error of the mean. AHI: apnea-hypopnea index, APAP: automatic positive airway pressure, CPAP: continuous positive airway pressure

을 호소하였고 3명(33.3\%)이 효과가 없음을 이유로 구매하지 않았다고 하였다(Table 3).

4개월간의 PAP 기기에 저장된 데이터에서 하루 4시간 이상 지속적 사용 비율은 $\mathrm{CPAP}$ 에서 $74.0 \%$, APAP에서 $65.1 \%$ 로 두 그룹 간에 통계학적인 유의성이 없었다. PAP 사용 후 $\mathrm{AHI}$ 는 $\mathrm{CPAP}$ 에서 2.7, APAP에서 2.6으로 두 그룹 모두 PAP 치 료에 효과를 보였고 두 그룹 간에 통계적인 차이는 보이지 않았다(Table 4). 그러나 PAP의 적정 압력이 CPAP에서 8.6, $\mathrm{APAP}$ 에서 10.6으로 두 그룹 간에 통계적인 유의성이 있었으 며 $(p=0.010), 95$ th percentile leak이 CPAP에서 13.0, APAP 에서 20.4으로 두 그룹 간에 통계적인 유의성이 있었다 $(p=$ 0.014)(Table 4).

\section{고 찰}

$\mathrm{PAP}$ 는 중등도 이상의 OSA 환자에서 우선적으로 처방되 는 치료 방법으로 구강 내 장치나 비강 및 인두 부위에 대한 수술에 비해 장기간의 치료 효과가 좋다는 많은 의학적 증거 를 가지고 있으며, 지속적으로 사용하였을 때 OSA로 진단된 환자 중 $85 \%$ 가 치료 효과를 볼 수 있는 치료 방법이다. ${ }^{21)}$ 그 러나 뛰어난 치료 효과에도 불구하고 PAP 치료에 대한 순응 도는 국외의 경우 28 83\%로 다양하게 나타나고, ${ }^{14)}$ 국내의 경우 $40 \%$ 전후로 낮게 나타나고 있는 실정이다. ${ }^{15)}$ 본 연구에
서는 $\mathrm{CPAP}$ 치료에 대한 순응도가 $76 \%$, APAP 치료에 대한 순응도가 $63 \%$ 로 국외에서 연구된 자료와 비교했을 때 각 $\mathrm{PAP}$ 기기에 따른 순응도는 선행연구와 비슷한 결과를 보였 다고 볼 수 있다.

PAP 치료의 순응도에 영향을 미치는 인자로는 처방하는 의사와 관련된 인자, 치료받는 환자와 관련된 인자, 그리고 $\mathrm{PAP}$ 장비와 관련된 인자로 나누어 볼 수 있다. ${ }^{3)}$ 처방의는 환 자에게 PAP 치료의 목적, 효과 및 발생할 수 있는 부작용 등 에 대한 자세한 설명과 지속적인 추적 관찰을 통해 PAP 치 료의 순응도를 높일 수 있다. ${ }^{22)}$ 환자의 나이, 환자의 기저질환, $\mathrm{OSA}$ 의 중등도와 관련된 다양한 변수들(AHI, 최저산소포화 도, $\mathrm{ESS})$ 과 같이 환자와 관련된 인자들에 대해 많은 연구가 이루어져왔으며, ${ }^{23,24)} \mathrm{OSA}$ 환자의 나이가 많을수록, $\mathrm{ESS}$ 점 수가 높을수록, 기저질환의 정도가 심할수록, $\mathrm{BMI}$ 와 $\mathrm{AHI}$ 가 높을수록, 산소포화도가 낮을수록 PAP 치료의 순응도가 높 다고 보고하였다. 23,24)

본 연구는 중증 OSA의 치료에 있어 PAP 장비의 종류가 구매율과 순응도에 영향을 미치는 인자가 될 수 있는지에 대 해 분석하였다. 먼저 $\mathrm{CPAP}$ 와 $\mathrm{APAP}$ 기기로 4 개월간 치료 후 $\mathrm{AHI}$ 값은 $\mathrm{CPAP}$ 의 경우 2.7, $\mathrm{APAP}$ 의 경우 2.6으로 $\mathrm{CPAP}$ 와 $\mathrm{APAP}$ 치료 모두 중증의 OSA 환자에서 치료 효과를 보였으 며 두 군 간에 통계적으로 유의한 차이를 보이지 않았다. 하 지만 PAP을 처방받은 후 4주간의 임대 사용 후 $\mathrm{CPAP}$ 와 $\mathrm{APAP}$ 의 구매율에서 $\mathrm{CPAP}$ 가 $84 \%$, $\mathrm{APAP}$ 이 $55 \%$ 를 보여 통계적으로 유의한 차이가 있음을 확인할 수 있었다. PAP 기기를 구매한 환자들을 대상으로 한 4 개월간의 PAP 치료 후 순응도에 있어서는 CPAP가 76\%, APAP이 63\%로 통계학 적으로 유의한 차이를 보이지는 않았지만 $\mathrm{CPAP}$ 에서 $\mathrm{APAP}$ 보다 순응도가 높은 경향을 보였다. 비구매 사유를 보면 비강 마스크 불편감이 $\mathrm{CPAP}$ 에서 $75 \%, \mathrm{APAP}$ 에서 $66 \%$ 로 가장 많은 부분을 차지하는 것을 알 수 있다.

$\mathrm{CPAP}$ 와 APAP를 처방받아 임대 사용 후 구매한 환자들 의 4 개월간 사용한 PAP 기기 내의 자료를 분석 시 적정 압 력이 $\mathrm{CPAP}$ 에서 8.6, $\mathrm{APAP}$ 에서 10.6으로 두 그룹 간에 통계 적으로 유의한 차이가 있었고 95th percentile leak 또한 CPAP에서 13.0, APAP에서 20.4로 두 그룹 간에 통계적으로 유의한 차이를 보였다. 중증의 OSA 환자에서 CPAP 기기에 비해 APAP 기기에서 적정 압력과 95th percentile leak이 더 높았다는 것을 알 수 있었고 이는 본 연구의 비구매 사유 중 대부분을 차지하는 비강 마스크 불편감과 연관되어 구매율 과 순응도에 영향을 미쳤을 것으로 여겨진다. 다른 연구에서 밝혔듯이 환자들은 PAP 사용 시 흔히 호소하는 불편 사항 으로 비강 마스크의 틈이나 구강으로 공기가 새거나, 높은 
양압으로 인해 호흡 시, 특히 숨을 내쉴 때의 거북함 등으로 인해 순응도가 떨어진다는 보고와 유사한 연구 결과를 보여 주었다. ${ }^{24)}$ 그리고 $\mathrm{CPAP}$ 의 경우 처방 후 적정 압력을 결정하 기 위해 병원에서 수면다원검사 기술자에 의해 titration이 시 행되는데 이 과정에서 환자는 $\mathrm{CPAP}$ 기기에 익숙해졌거나 또는 비강 마스크의 적절한 사용 방법을 인지해 $\mathrm{CPAP}$ 의 구 매율이 높은 결과값을 보였을 수도 있다.

수면 관련 호흡장애를 감지하기 위해 CPAP 기기에서 사용 되는 수동 압력 적정방법과 APAP 기기에서 사용되는 자동 압력 적정방법은 적용되는 알고리즘뿐만 아니라 기록되고 해석되는 신호에서 차이가 있다. ${ }^{19)} \mathrm{CPAP}$ 의 경우 효과적인 $\mathrm{CPAP}$ 기기의 적정 압력 결정은 일반적으로 하룻밤 사이의 수면다원검사 동안 수면다원검사실의 기술자가 수행하지만,25) $\mathrm{APAP}$ 의 경우 수면 시 변화하는 기도 저항에 대해 APAP 기 기가 설정된 압력 내에서 자동으로 기계 자체의 알고리즘을 통해 적정 압력을 조절하게 된다. ${ }^{26)}$ 따라서 OSA 환자의 치료 에 있어 $\mathrm{CPAP}$ 기기의 경우 비강 마스크 착용 시 고정된 일 정한 압력이 적용되는 반면 $\mathrm{APAP}$ 기기의 경우 압력이 자동 으로 변한다는 차이를 보인다.

본 연구 결과에서 4개월간 PAP 기기에 저장된 정보에 따 르면 $\mathrm{CPAP}$ 기기에 비해 $\mathrm{APAP}$ 기기에서 적정 압력과 95 th percentile leak이 더 높게 측정이 되었는데 이는 두 가지로 해 석이 가능하다. 첫째, 수면 기술자에 의해 적정압력검사를 받 는 동안 $\mathrm{CPAP}$ 기기와 비강 마스크 사용법에 대해 익숙해지 는 $\mathrm{CPAP}$ 환자와 달리 APAP 환자의 경우 환자 본인이 스스 로 APAP 기기와 비강 마스크를 사용하므로 비강 마스크의 부적절한 착용으로 인해 $\mathrm{APAP}$ 사용 시 공기 누출이 $\mathrm{CPAP}$ 에 비해 높을 수 있고 이로 인한 비강 마스크 착용의 불편감 이 증가하여 구매율이 낮은 결과 ${ }^{27}$ 를 가져왔을 수 있다. 둘째, $\mathrm{APAP}$ 기기의 자동 적정 압력을 측정하는 알고리즘 이상이 나 APAP 기기 내에 하악의 움직임을 감지하여 구강 열림을 인지하는 자기 센서의 이상 ${ }^{28)}$ 또는 수면 기술자에 의해 적정 압력검사를 거치지 않음으로 인해 APAP 기기의 적정 압력 이 높아지고 결과적으로 95th percentile leak이 많아져 ${ }^{29}$ $\mathrm{APAP}$ 를 사용하는 환자들의 수면 중 비강 마스크 불편감이 증가하여 구매율을 낮추는 결과 ${ }^{34}$ 를 가져왔을지도 모른다. 첫째 문제로 인한 경우 주기적인 환자 교육과 환자 상담을 통해 환자의 비강 마스크 착용 문제점을 보완해 나간다면 $\mathrm{APAP}$ 의 구매율을 높여 결과적으로 순응도를 더 높일 수 있 지만, 둘째 문제의 경우 APAP 기기의 작동 메커니즘 또는 적 정 압력 범위를 결정하는 알고리즘의 이상으로 인한 것으로 $\mathrm{APAP}$ 기기의 한계를 인식하고 보완해 나가야 할 것으로 보 인다.
중등도 이상의 OSA 환자의 치료에 있어 PAP의 낮은 순응 도는 치료 효과를 낮추는 중요한 문제로 이전의 연구들은 대 부분 환자 자체의 인자를 중심으로 보고되어 왔으나 우리의 이번 연구는 PAP 종류에 따른 적정 압력과 95th percentile leak의 차이점을 비교해 보고 그에 따른 구매율과 순응도를 비교한 연구이다. 비록 본 연구에서 $\mathrm{CPAP}$ 와 $\mathrm{APAP}$ 의 순응 도에서 통계적인 유의성은 없었지만 PAP 사용 시 95th percentile leak과 적정 압력이 CPAP에 비해 APAP가 더 높았 으며, $\mathrm{APAP}$ 의 구매율은 $\mathrm{CPAP}$ 에 비해 통계적으로 유의하게 낮은 결과를 보여주었다. 95th percentile leak과 적정 압력 의 선후 관계를 정확히 알 수는 없지만 이러한 두 인자들이 $\mathrm{APAP}$ 를 사용하는 환자의 구매율에 영향을 미쳤을 가능성 도 있다. 따라서 중증의 OSA 환자에게 PAP 기기를 처방함에 있어 $\mathrm{CPAP}$ 를 처방하거나 혹은 $\mathrm{APAP}$ 를 처방하더라도 주기 적인 환자와의 면담을 통하여 비강 마스크 착용 이상으로 인 한 환자의 불편감을 해소하고 APAP 기기의 작동 한계를 보 완하여 APAP 사용에 있어 환자의 구매율을 높여 결과적으 로 순응도를 높이는 것이 중요하다고 생각된다.

이번 연구의 한계점은 $\mathrm{PAP}$ 기기의 처방 수가 적고 $\mathrm{PAP}$ 기 기를 구매한 환자들의 PAP 기기 내 데이터를 통해 비구매의 원인을 유추하여 결과 해석에 영향을 줄 수 있으며, CPAP와 $\mathrm{APAP}$ 의 구매 가격 차이 또한 결과에 영향을 미칠 수 있다. 후향적 분석이 가지는 연구 자체의 한계점이 있을 수 있으므 로 추후에 이러한 결과를 확실히 하기 위해 장기간의 추적 관찰을 포함한 랜덤 방식의 전향적 연구가 필요할 것으로 생 각된다.

중증의 OSA 환자의 치료에 있어 PAP 사용 시 높은 공기 유출 정도와 높은 적정 압력이 $\mathrm{CPAP}$ 와 $\mathrm{APAP}$ 의 구매율과 순응도에 영향을 미치는 인자일 수 있다. 따라서 APAP의 처 방 후 주기적인 환자 면담을 통해 환자의 비강 마스크 불편감 을 감소시키고 APAP 기기를 보완하여 PAP 기기의 구매율 을 높여 결과적으로 환자의 순응도를 높이는 것이 중요하다.

\section{Acknowledgments}

This work was supported by clinical research grant from Pusan National University Hospital in 2019.

\section{Author Contribution}

Conceptualization: Kyu-Sup Cho. Data curation: Ilyoung Cho, Sung-Dong Kim, Sue Jean Mun. Formal analysis: Ilyoung Cho, Kuen-Ik Yi. Funding acquisition: Kyu-Sup Cho. Investigation: Ilyoung Cho, Kyu-Sup Cho. Methodology: Ilyoung Cho, Hwabin Kim. Project administration: Ilyoung Cho. Resources: Ilyoung Cho. Software: Hwabin Kim. Supervision: Kuen-Ik Yi, Sung-Dong Kim, Sue Jean Mun, Kyu-Sup Cho. Validation: Ilyoung Cho. Visualization: Hwabin Kim. Writing - original draft: Ilyoung Cho, Kyu-Sup Cho. Writing — review \& editing: Kyu-Sup Cho. 


\section{ORCIDs}

Kyu-Sup Cho

https://orcid.org/0000-0002-4381-6996

Ilyoung Cho

\section{REFERENCES}

1) Partinen M, Guilleminault C. Daytime sleepiness and vascular morbidity at seven-year follow-up in obstructive sleep apnea patients. Chest 1990;97(1):27-32.

2) Kales A, Caldwell AB, Cadieux RJ, Vela-Bueno A, Ruch LG, Mayes SD. Severe obstructive sleep apnea--II: Associated psychopathology and psychosocial consequences. J Chronic Dis 1985;38(5):427-34.

3) Kim HY, Jang MS. Improving compliance for continuous positive airway pressure compliance and possible influencing factors. Korean J Otorhinolaryngol-Head and Neck Surg 2014;57(1):7-14.

4) Nieto FJ, Young TB, Lind BK, Shahar E, Samet JM, Redline S, et al. Association of sleep-disordered breathing, sleep apnea, and hypertension in a large community-based study. Sleep Heart Health Study. JAMA 2000;283(14):1829-36.

5) Kim J, In K, Kim J, You S, Kang K, Shim J, et al. Prevalence of sleep-disordered breathing in middle-aged Korean men and women. Am J Respir Crit Care Med 2004;170(10):1108-13.

6) Sullivan CE, Issa FG, Berthon-Jones M, Eves L. Reversal of obstructive sleep apnoea by continuous positive airway pressure applied through the nares. Lancet 1981;1(8225):862-5.

7) Parish JM, Lyng PJ. Quality of life in bed partners of patients with obstructive sleep apnea or hypopnea after treatment with continuous positive airway pressure. Chest 2003;124(3):942-7.

8) Engleman HM, Martin SE, Deary IJ, Douglas NJ. Effect of CPAP therapy on daytime function in patients with mild sleep apnoea/ hypopnoea syndrome. Thorax 1997;52(2):114-9.

9) Loube DI, Gay PC, Strohl KP, Pack AI, White DP, Collop NA. Indications for positive airway pressure treatment of adult obstructive sleep apnea patients: A consensus statement. Chest 1999;115(3): 863-6.

10) Hoffstein V. Review of oral appliances for treatment of sleepdisordered breathing. Sleep Breath 2007;11(1):1-22 .

11) Weaver TE, Maislin G, Dinges DF, Younger J, Cantor C, McCloskey $\mathrm{S}$, et al. Self-efficacy in sleep apnea: Instrument development and patient perceptions of obstructive sleep apnea risk, treatment benefit, and volition to use continuous positive airway pressure. Sleep 2003; 26(6):727-32.

12) Vital FM, Saconato H, Ladeira MT, Sen A, Hawkes CA, Soares B, et al. Non-invasive positive pressure ventilation (CPAP or bilevel NPPV) for cardiogenic pulmonary edema. Cochrane Database Syst Rev 2008;(3):CD005351.

13) Sin DD, Mayers I, Man GC, Pawluk L. Long-term compliance rates to continuous positive airway pressure in obstructive sleep apnea: A population-based study. Chest 2002;121(2):430-5.

14) Nowak C, Bourgin P, Portier F, Genty E, Escourrou P, Bobin S. [Nasal obstruction and compliance to nasal positive airway pressure]. Ann Otolaryngol Chir Cervicofac 2003;120(3):161-6.

15) Han EK, Yoon IY, Chung S. The compliance and effect of CPAP in obstructive sleep apnea syndrome. Sleep Med Psychophysiol 2006; 13(2):52-8

16) Berkani M, Lofaso F, Chouaid C, Pia d'Ortho M, Theret D, GrillierLanoir V, et al. CPAP titration by an auto-CPAP device based on snoring detection: A clinical trial and economic considerations. Eur Respir J 1998;12(4):759-63.

17) Berry RB, Parish JM, Hartse KM. The use of auto-titrating continuous positive airway pressure for treatment of adult obstructive sleep apnea. An American Academy of Sleep Medicine review. Sleep 2002;25(2): 148-73.

18) d'Ortho MP. Auto-titrating continuous positive airway pressure for treating adult patients with sleep apnea syndrome. Curr Opin Pulm Med 2004;10(6):495-9.

19) Randerath WJ, Galetke W, David M, Siebrecht H, Sanner B, Rühle K. Prospective randomized comparison of impedance-controlled autocontinuous positive airway pressure (APAP(FOT)) with constant CPAP. Sleep Med 2001;2(2):115-24.

20) Kribbs NB, Pack AI, Kline LR, Smith PL, Schwartz AR, Schubert $\mathrm{NM}$, et al. Objective measurement of patterns of nasal CPAP use by patients with obstructive sleep apnea. Am Rev Respir Dis 1993; 147(4):887-95.

21) Teschler H, Berthon-Jones M. Intelligent CPAP systems: Clinical experience. Thorax 1998;53 Suppl 3:S49-54.

22) Basner RC. Cardiovascular morbidity and obstructive sleep apnea. N Engl J Med 2007;356(17):1751-8.

23) Dhillon S, Chung SA, Fargher T, Huterer N, Shapiro CM. Sleep apnea, hypertension, and the effects of continuous positive airway pressure. Am J Hypertens 2005;18(5 Pt 1):594-600.

24) Aloia MS, Stanchina M, Arnedt JT, Malhotra A, Millman RP. Treatment adherence and outcomes in flexible vs standard continuous positive airway pressure therapy. Chest 2005;127(6):2085-93.

25) Kushida CA, Littner MR, Morgenthaler T, Alessi CA, Bailey D, Coleman J Jr, et al. Practice parameters for the indications for polysomnography and related procedures: An update for 2005. Sleep 2005;28(4):499-521.

26) Parish JM, Miller BW, Hentz JG. Autotitration positive airway pressure therapy in patients with obstructive sleep apnea who are intolerant of fixed continuous positive airway pressure. Sleep Breath 2008;12(3):235-41.

27) Valentin A, Subramanian S, Quan SF, Berry RB, Parthasarathy S. Air leak is associated with poor adherence to autoPAP therapy. Sleep 2011;34(6):801-6.

28) Lebret M, Arnol N, Martinot JB, Lambert L, Tamisier R, Pepin JL, et al. Determinants of Unintentional Leaks During CPAP Treatment in OSA. Chest 2018;153(4):834-42.

29) Genta PR, Lorenzi-Filho G. Sealing the leak: A step forward in improving CPAP adherence. Chest 2018;153(4):774-5.

30) Woehrle H, Arzt M, Graml A, Fietze I, Young P, Teschler H, et al. Effect of a patient engagement tool on positive airway pressure adherence: Analysis of a German healthcare provider database. Sleep Med 2018;41:20-6. 